\title{
INTERNATIONALLY-EDUCATED ENGINEERS' INSIGHTS INTO THE SOCIAL Responsibilities Embedded in the Canadian EngINeERING Profession
}

\author{
Marcia R. Friesen and Jillian Seniuk Cicek \\ Centre for Engineering Professional Practice \& Engineering Education \\ University of Manitoba, Winnipeg, MB R3T 5V6 \\ marcia.friesen@umanitoba.ca, umseniuk@myumanitoba.ca
}

\begin{abstract}
Drawing from data collected as part of a larger study, this paper focusses specifically on internationally-educated engineers' (newcomers to Canada) insights and experiences of the social role and social responsibility inherent in the Canadian engineering profession. The study participants were individuals who had completed a formal foreign credentials recognition process through a qualifications recognition program at the University of Manitoba, and who have achieved professional licensure in Manitoba. Data were collected from 23 internationally-educated engineers through long one-on-one and group interviews over a period of two years. The work uses a conceptual framework of professional practice as the development of moral conscience. The data demonstrate that through engagement with the regulatory process including rightto-title, right-to-practice, and the Code of Ethics, and through one's day to day engineering practice, participants assimilated an understanding of the practice of professional engineering in Canada as being rooted in a professional community with explicit and stable social responsibilities.
\end{abstract}

Keywords: Immigrant engineers, internationally-educated engineers, qualifications recognition, engineering ethics.

\section{INTRODUCTION}

The names we give to things matters. Occasionally we call things by the same name for so long that we fossilize our idea of its meaning and its value. In the discourse of engineering education, we may assume a shared understanding of terms like 'design', 'teamwork', 'communication' and 'engineering ethics', and we rarely take an opportunity to engage with colleagues on our individual or collective conceptions and whether they match. The fossilization of these ideas can be inhibiting the growth of a community, which needs diverse perspectives that at times challenge one another.

Changing the name of a concept opens the door to seeing it from a new perspective. For example, in North
America, references to 'disabled' or 'disability' in society have been largely replaced with references to 'accessibility,' shifting the focus from the individual to the environment and the environment's impact on the individual. When scanning materials from government and public institutions, one notes that the word 'newcomer' is preferred to the term 'immigrant' in public discourse. The term 'newcomer' allows us to break with historical ideas we may hold of the profile of an immigrant as a low-skilled labourer. It also connotes that the status is temporary; soon, this person will also be a Canadian, no longer set apart. These changes, although subtle, may reflect deeper personal, corporate, or societal shifts in our values. Re-naming things presents an opportunity to come face-to-face with long-held beliefs and values that were largely invisible and from there, move to new understandings.

The same can be applied to the definition of the word, profession. Different sources name between four to seven key characteristics of a profession, commonly including: a specialized body of knowledge attained through intensive education and training; authority through self-regulation; high standards of achievement and conduct enshrined in a Code of Ethics; a commitment to continued learning; and public service as its primary purpose [1].

Yet, many practicing engineers will anecdotally reflect that one's personal concept as a professional and one's understanding of professional ethics and practice is developed individually through the somewhat accidental circumstances that coalesce to become the corporate culture and one's group of professional colleagues, rather than being developed intentionally and collectively.

Cultural differences add another layer of complexity to attempts to agree on professional ethics and practice. Commonly cited professional competencies like "teamwork", "professional communication", "initiative", "management skills" vary in their manifestations from culture to culture. A highly desirable professional trait in one culture - for example, strong deference to authority many appear in another culture as a lack of initiative and confidence and hence, as a professional liability. Similarly, different cultures have different approaches to the amount and specificity of data required before moving 
forward on a decision. When viewed through different cultural lenses, interpretations of one's level of professionalism, regard for public safety, and attitude toward risk are quickly drawn [2].

This work examines how 23 internationally-educated engineers (newcomers to Canada) developed a personal concept of the engineering profession through their initial engineering work experiences in Canada, and in particular, through their insights and experiences of the social role inherent in the Canadian engineering profession. These insights were embedded in newcomers' interactions with the professional regulatory framework and through emerging perceptions of public interest and professional responsibility. The data demonstrated changed perspectives, and the data are further interpreted through a framework [3] that encourages reflection on the lexicon of professional practice and the re-naming of things in order to gain new perspectives.

This work is unique and timely within the research literature around the integration of internationallyeducated professionals into regulated professions in Canada. Much research focuses on newcomers' experiences to achieve professional registration through technical assessment and confirmation, on labour market entry and career development pathways, and on cultural challenges including occupation-specific language and communication requirements [4]-[8]. No prior work was readily identified in the engineering education research literature that critically examines whether professional engineers (within and/or across cultures) share common understandings of what constitutes 'professionalism', and 'ethics' in professional practice.

\section{CONCEPTUAL FRAMEWORK}

In this work, data are interpreted through a framework of moral practice proposed by Green [3]. The framework itself is aligned with an objective to examine and challenge the traditional lexicon of professional practice and potentially open up new insights. It provides a broad view of professional knowledge and practice with vocabulary that parallels many concepts found in North American textbooks on engineering ethics and professionalism. Green's focus is on moral education, that being the development of moral practice and moral practitioners. This development is articulated as the formation of conscience, or the capacity of each person to be their own judge. According to Green, conscience speaks in five 'voices':

1. Conscience as craft: one's technical skill, coupled with the ability to judge one's own performance (for example, to feel satisfaction, pride, shame, embarrassment, etc.). A conscience of craft underlies our concern with excellence in our work.
2. Conscience as membership within a community, attachment to a community, and acquisition of the norms of the community in an ethic of caring and responsibility. Membership is said to be strong when one's behaviour conforms to a certain pattern, and critically, when the departures from normative behaviour have the capacity to elicit emotions such as guilt, shame, anxiety, or fear. Norms become most visible and obvious when a member departs from them. Further, conscience as membership asks the question, 'what is good for $u s$ to do' rather than 'what is good for me to do'.

3. Conscience as sacrifice, or the necessity of performing actions that go beyond simple duty. Sacrifice is not defined as self-sacrifice or injustice relative to oneself, but rather as indifference to self, or a disinterest in the self in an act that goes beyond obligation. Such actions are most easily found in the context of friendships and memberships. They are cultivated in the practices of keeping promises, speaking honestly, keeping contracts, and preserving confidences.

4. Conscience as memory: addressing the human need for rootedness or fixedness, or an anchoring in the knowledge of one's social inheritance. Rather than commitment - which is a personal choice - the idea of rootedness refers to the ancestry that one cannot choose, and then claiming it as one's own and working upon and from it. The conscience of memory is developed through narrative and story-telling of members.

5. Conscience as imagination: a vision and voice from within the community, carrying a critique-ful tone that speaks to the disconnect between what is and what could be. The voice from within the community has the capacity to draw new metaphors, challenge established ideas, articulate a vision for the future, and motivate the community toward these new understandings and fresh beginnings.

In this work, these five consciences are bridged to engineering notions of technical skill (craft), professional membership (membership), service (sacrifice), history (memory), and leadership (imagination), respectively. As such, these consciences represent re-naming, encouraging insights by viewing experiences through different lenses.

These notions also find expression through professional practice and through the regulatory context of professional engineering in Canada, which provides a second portion of the conceptual framework through which to interpret the data. In Canada, regulation of the engineering profession is a provincial / territorial responsibility. Throughout Canada, registration with a provincial engineering association (regulatory body) is a legal requirement for right-to-title and right-to-practice as a professional engineer and the use of the post-nominal 
P.Eng. These credentials in turn facilitate professional employment and career mobility. Requirements for registration with a provincial association are largely commensurate in each Canadian province and territory, and consist of academic qualification through an undergraduate degree in engineering from an accredited Canadian program or an assessed equivalent in order to reach the first stage of registration, denoted Engineering Intern. Subsequently, four years of supervised practice and successful completion of a national ethics and law exam are required for eligibility for full registration as a professional engineer (P.Eng.) and the subsequent interprovincial mobility of one's status.

Once registered as a professional engineer, adherence to the association's Code of Ethics is mandatory. The Code of Ethics for engineers registered in Manitoba [9] parallels that of many professional bodies and technical societies. It articulates responsibilities under five fundamental canons that obligate the professional engineer to: obey the laws of the land; regard the public interest as one's prime responsibility in all professional work; meet responsibilities toward one's own ongoing competence; and uphold the integrity of the profession and to one's colleagues.

In this work, the participants are navigating this intersection of the concrete processes and artifacts of the regulatory context, and how this context lend itself to a (re)formation of the consciences of professional practice and (re)formation of a personal identity as a moral practitioner.

\subsection{Research Question}

The data were interpreted in response to the following research question: How do newcomers perceive the social and ethical responsibilities embedded in the Canadian engineering profession and in the individual professional engineers?

\section{METHODOLOGY}

The data used in this work were part of a larger study designed to examine the perspectives and experiences of internationally-educated engineers in their transition into the Canadian engineering profession, including professional registration and the first year of professional engineering work in Canada [10][11]. The study participants were individuals who had completed a formal foreign credentials recognition process through the Internationally-Educated Engineers Qualification (IEEQ) Program at the University of Manitoba, Canada, and who had achieved professional licensure (P.Eng. registration) with Engineers Geoscientists Manitoba. Data were collected from 23 internationally-educated engineers through one-on-one and group interviews over a period of two years.

All participants immigrated to Canada after 2002. The participants were professional civil, mechanical, industrial, electrical, and electronics engineers. Participants ranged in age from early thirties to midfifties. Participants represented 13 countries of origin in South America, Africa, Central Europe, and Asia. They held an average of nine years of professional engineering experience prior to immigration. The years of completion of the formal credentials recognition program ranged from 2004 to 2011, and the year of professional registration (P.Eng.) in Canada ranged from 2006 to 2014. At the time of the study, all were working in professional engineering positions with employment divided fairly equally between private and public sector employers including consulting engineering services, manufacturing, agribusiness, construction, utilities, and government.

Data collection consisted of an initial focus group, a one-on-one interview, and a final focus group. All 23 newcomers in the study participated in at least one session; collectively, there were 38 data collection events. The interview protocols were designed to focus on participants' experiences and perceptions of their first year of engineering work experience in Canada, probing their learning, growth, attendant emotions, professional contributions, participation, identities, and critical encounters.

Interview transcripts were coded and analyzed in a constant comparative method to discover emergent patterns and themes [12][13]. Findings were evaluated for authenticity through member checks with research subjects, triangulation, and peer debriefing. The conclusions are assimilated into the larger framework of the research.

\section{FINDINGS}

The volume of data illuminated a wide range of themes, detailed in other publications. Notable findings include the interpretation of an engineering qualifications process as a decidedly non-technical process of social and cultural capital acquisition [10] and the interpretation of newcomers' professional integration as a boundary crossing, with inherent conflicts and power dynamics between personal agency and liberal fairness ideals [11]. This paper focusses attention on themes that emerged from the data that related specifically to the social role of the engineering profession and the ethical role of its practitioners in the Canadian context. These data can be interpreted as the evolution of a newcomer's sense of professional community encompassed in Green's conscience as membership and conscience as memory. The findings are presented narratively to allow the richness of the data to be illuminated. 
Green defines one element of moral practice as membership within a community, attachment to a community, and acquisition of the norms of the community in an ethic of caring and responsibility. $\mathrm{He}$ further defines another element of moral practice as memory, addressing the human need for rootedness or fixedness, or an anchoring in the knowledge of one's social inheritance. He differentiates this from the notion of commitment, which is a personal choice, and rather refers to the rootedness as an ancestry that one claims as one's own, and then working upon and from it. The idea of a professional ancestry is particularly interesting in the context of newcomers. It implies a two-way adoption of sorts, since the ancestry of a profession can be argued to be culturally-mediated. The actors and artifacts that are seminal engineering milestones in Canada and which subsequently shape a common understanding of the profession's character and role will differ from the actors and artifacts in another country. A small sample of such actors and artifacts in Canadian engineering may include Rudyard Kipling's Ritual of the Calling of an Engineer, the iron ring, and significant recent Canadian events such as the Charbonneau Commission in Quebec enacted in 2011 to investigate public contract administration in the construction industry and the Algo Centre Mall collapse in Elliot Lake, Ontario in 2012. These themes of moral practice as membership and as memory emerged in the data through participants' interactions with the professional regulatory framework and through their emerging perceptions of public interest and professional responsibility.

The development of 'conscience as membership' and 'conscience as memory,' understood as attachment to a community, acquisition of the norms of the community, and anchoring in the understanding of the profession's social inheritance were fostered through the explicit regulatory framework. Many participants commented that the engineering profession in Canada "has an explicit social responsibility" that is absent in the profession in their home countries. Initially, newcomers encounter this idea through the regulatory framework that controls rightto-title and right-to-practice for all engineers, and which facilitates qualifications recognition of newcomers with foreign credentials.

When asked to identify the most important knowledge or skills needed to help transition into the engineering profession, one participant stated,

understanding what makes an engineer - the university degree vs. the licensing process, and the responsibility and ethics. [The regulatory body's mandate for] professional regulation is hard to understand because for many, there is no similar context in our home country. Even though we had contact with [the regulatory body] many times before entering the IEEQ Program, [its role] wasn't fully clear until we got it explained in the program.

Another participant stated, "In Canada, the standards are much higher, not technical standards, but regulatory standards - for example, the right to call yourself an engineer and ethical standards", followed by, "in our home country, our personal reputation might be at stake but in Canada, it extends to the reputation of your organization and the public."

The regulatory framework includes adherence to a professional Code of Ethics which makes the protection of the public interest the explicit and primary mandate in any engineering work. Public interest is often defined as public safety, but it also applies more broadly to public interest to maintain economic growth and opportunity, social responsibility and equity, and environmental sustainability. In addition to the right-to-title and right-topractice, the Code of Ethics within the regulatory framework also mediated newcomers' understanding of the profession's social responsibility.

For example, many participants commented that this perspective on protecting the public interest is not a part of the 'engineering conscience' in their home countries, as demonstrated in engineers' responsibility with respect to their own safety, obligations to peer-monitor, and the safety of the public. One participant gave an example of Canadian safety standards for entering confined spaces where two people need to be present, air quality monitored, safety harnesses used, and other precautions. He continued, "Our thinking has been changed. You don't compromise safety here. But you have to be able to afford that too, it's a huge cost".

A view of the role of safety in design was also identified by participants as critical new knowledge: "In Canada, when engineering for safety or for economy, economy is secondary," and "safety first: I started to grasp that within IEEQ, but it was really developed postIEEQ".

This newcomer's story is that of a mechanical engineer from Argentina integrating the public interest into his selfconcept as an engineer. His 27 years of professional experience were in designing HVAC systems for industrial processes. The years of experience are split almost evenly between Argentina and Canada. $\mathrm{He}$ commented,

To me the most remarkable difference in Canada is the social aspect of engineering. I had never included the public in my mind before, or the public safety or the public interest. I was always dealing with a client and you say, "This is the equipment," and that's it. For example, I could think, "What do you mean, 'public safety' if I'm designing cooling towers?" right? To me, the client was the client. The client was not the public. I became much more conscious of the 
client as the public when I ran the engineering department at my former employer [in Canada] than when I was a design engineer [in Argentina] designing equipment. For example, when I went to visit Buenos Aires earlier this year, I ran into a former client and I looked at the equipment I had supplied to him all those years ago, and I'm thinking, "Oh my god, this is not even safe! Why is this not tied up?" or "Why is this not secured?" I looked at him and asked "If you ever lose the water supply to this piece of equipment, it is only going to weigh 200 pounds, and then the wind will carry it right off the roof!" $\mathrm{He}$ answered, "The pipes are going to keep it in place." That's the mentality of the guy, and I thought, "Well, that was me fifteen years ago." But today I think, "I'm not sure the pipes are going to keep it in place."

He continued,

I was with a customer last week looking at something somebody sold them. He called me saying, "Can you come and take a look?" So I went and took a look, and he said, "Do you see any problem of this?" and I said, "Well, I would change this and I would change that, but then I think it's okay." And then he asked, "Would you red-mark the drawing?"

The participant chucked and said, "I said 'no'." I wouldn't red-mark the drawing because I gave him an informal opinion. To red-mark the drawing, my obligation would be to do a full set of calculations and document the recommendations. Also, I don't have control over the entire design; I'm just commenting on this one little part. So, to red-mark the drawing is a place that I don't want to go. But, I probably would have felt okay doing that in the past write a note on the drawings saying to revise this or revise that. I probably would have done that before I was aware of the implications of my professional seal and signature on the drawing.

While this participant reflected on the concept of safety engineering at greatest length, many participants remarked that explicit consideration of the public interest, initially through a consideration of public safety was something of which they only overtly became aware and began to understand and adopt once they started practicing professional engineering in Canada.

Closely related, many participants identified professional and social responsibility as an area of critical new understandings. This can also be interpreted as evidence of 'conscience as membership' and 'conscience as memory' as attachment to a community, acquisition of the norms of the community, and anchoring in the understanding of the profession's social inheritance.
These were developed more tacitly, learned by observation rather than regulatory process, and are demonstrated in one participant's comment that he "really learned the meaning of being an engineer, the role in society, responsibilities, ethical and moral obligations." Another continued,

There is a social responsibility in the profession here that is not present in my home country. In Canada, the engineer takes more responsibility. In my home country, we are strictly technical people. Here, you not only have to have technical skills, you have to think broader, $[\ldots$ of $]$ the implications of your work over time.

While excellent engineering happens all over the world, a civil engineer spoke of the unlikelihood that an engineer would be held judicially liable for an engineering failure in his home country:

[Engineering in Canada] is a big responsibility. At home, we do try our best, but there are no big consequences if otherwise. For example if a bridge collapses in my country, nothing would happen. I can't imagine an engineer in [my home country] going to court because a bridge collapsed.

Another remarked, "We come from countries with less regulations and control, we tend to be able to take more risks [in the home country] than a professional engineer can in Canada.

Participants were able to contextualize specific insights related to regulatory process, public safety, and professional responsibility within a broadened view of the engineering profession. One participant commented: "The engineering is not different, just the perception [of it]. The definition of professional engineering is different than I knew it before, [...][including] responsibility to clients, environment, and society, in a positive way." Another participant added,

the regulatory environment is strict, and perceptive responsibilities of improvisation, the decision-making processes are different. For example, in my home country, you are often burdened with lack of resources, so you improvise. Here, you cannot improvise, and you have to learn that very quickly. It is a matter of going with your gut vs. taking a systematic analytical approach. On the one hand, this [restriction on improvisation] is restrictive of innovation and creativity.

The data can be interpreted as demonstrating newcomers' development of conscience as memory and conscience as membership in the Canadian engineering profession. It is important to note that these newcomers did not lack moral practice prior to arriving in Canada, but that they experienced differences in the meaning of moral practice between their home countries and Canada, or 
more specifically, the scope of concerns inherent in moral practice. Through engagement with the regulatory process and achieving right-to-title and right-to-practice, through the intersection of the Code of Ethics and their engineering roles, and through their day to day engineering practice, these participants were able to assimilate an understanding of the practice of professional engineering in Canada as being rooted in a professional community with explicit and stable social responsibilities. The findings are also highly integrated with notions of identity and belonging [10][11][14], supporting the complexity of qualifications recognition processes.

\section{CONCLUSION}

The findings, interpreted as the development of 'conscience as membership' and 'conscience as memory' through attachment to a community, acquisition of the norms of the community, and anchoring in the understanding of the profession's social inheritance, bridge to engineering notions of professional membership and history, respectively. By examining professional identity through the newcomers' experiences and learnings, and by setting this learning within Green's lexicon of professional practice, engineering educators and practicing engineers have an opportunity for personal reflection on concepts of professional ethics. Whether considering the $\mathrm{CEAB}$ graduate attributes in engineering education, or professional practice across engineering industries and sectors, these newcomers' experiences and perceptions offer insights into how these ideas are embedded in our Canadian notion of engineering practice, and in our personal identities as engineers.

\section{Acknowledgements}

This work was supported by the University of Manitoba Research Grant program.

\section{References}

[1] Gordon C. Andrews, Canadian Professional Engineering and Geoscience: Practice and Ethics. Toronto, ON: Nelson, 2014 ( $5^{\text {th }}$ ed.), 472 pp. \{ISBN: 978-0-17-650990-3\}

[2] Lionel Laroche, Managing Cultural Diversity in Technical Professions. Amsterdam: Butterworth Heinemann, 2003, 236 pp. \{ISBN:0-7506-7581-0\}.

[3] Thomas F. Green, "The formation of conscience in an age of technology," American Journal of Education, vol. 94, no. 1, pp. 1-32, 1985.

[4] Association of Universities and Colleges of Canada, Mapping Canadian University Capacity, Expertise, and Key Issues Related to Foreign Credential Recognition of
Internationally-Educated Professionals, Final Report. Ottawa, ON, Canada: Association of Universities and Colleges of Canada, 2006.

[5] Noriko B. Boorberg, International Dentist Degree Students Educational Experiences, Perceptions, and Adaptation to the International Dentists Degree program at the University of Manitoba. Master Thesis, University of Manitoba, 2011. Available from https://mspace.lib.umanitoba.ca/handle/1993/5074

[6] Probe Research, A Program Evaluation of Pilot Bridge Programming for Internationally Educated Professionals. Winnipeg, MB, Canada: Council on Post-Secondary Education and Manitoba Advanced Education and Literacy, 2011.

[7] Probe Research, Facilitated Session May 9, 2011: Institutional Capacity for Bridge Programming Summary of Comments. Winnipeg, MB, Canada: Council on Post-Secondary Education and Manitoba Advanced Education and Literacy, 2011.

[8] Clea A. Schmidt, Jon Young, and David Mandzuk, "The integration of immigrant teachers in Manitoba, Canada: Critical issues and perspectives," Journal of International Migration and Integration, vol. 11, no. 4, pp. 439-452, 2010.

[9] Association of Professional Engineers and Geoscientists of Manitoba, Code of Ethics for the Practice of Professional Engineering and Professional Geoscience. Available from http://apegm.mb.ca/pdf/ethics00.pdf

[10] Marcia R. Friesen, “Immigrants' integration and career development in the professional engineering workplace in the context of social and cultural capital," Engineering Studies, vol. 3, no. 2, pp. 79-100, 2011.

[11] Marcia R. Friesen, "Professional integration as a boundary crossing: Changes to identity and practice in immigrant engineers in Canada," Engineering Studies, vol. 8, no. 3, pp. 189-211, 2016.

[12] John W. Creswell, Research Design: Qualitative, Quantitative, and Mixed Methods Approaches. Thousand Oaks, CA: SAGE, 2013 ( $4^{\text {th }}$ ed.), 273 pp. \{ISBN: 978-1452226101\}.

[13] Corrine Glesne and Alan Peshkin, Becoming Qualitative Researchers: An Introduction. White Plains, NY: Longman, 1992, 199 pp. \{ISBN: 9780801302954\}.

[14] Marcia R. Friesen, "Interpreting Immigrant Engineers' Professional Integration as a Process of Identity Development in Engineering," World Transactions on Engineering \& Technology Education, vol. 10, no. 4, pp. 226-235, 2012. 